\title{
Surveillance for Harmful Algal Bloom Events and Associated Human and Animal Illnesses - One Health Harmful Algal Bloom System, United States, 2016-2018
}

\author{
Virginia A. Roberts, $\mathrm{MSPH}^{1}$; Marissa Vigar, $\mathrm{MPH}^{1}$; Lorraine Backer, $\mathrm{PhD}^{2}$; Gabriella E. Veytsel, $\mathrm{MPH}^{1,3}$; Elizabeth D. Hilborn, DVM ${ }^{4}$; Elizabeth I. \\ Hamelin, MS $S^{5}$ Kayla L. Vanden Esschert, MPH ${ }^{1,3}$; Joana Y. Lively, MPH' ${ }^{1,6}$; Jennifer R. Cope, MD ${ }^{1}$; Michele C. Hlavsa, MPH ${ }^{1}$; Jonathan S. Yoder, MPH ${ }^{1}$
}

Harmful algal bloom events can result from the rapid growth, or bloom, of photosynthesizing organisms in natural bodies of fresh, brackish, and salt water. These events can be exacerbated by nutrient pollution (e.g., phosphorus) and warming waters and other climate change effects (1); have a negative impact on the health of humans, animals, and the environment; and damage local economies (2,3). U.S. harmful algal bloom events of public health concern are centered on a subset of phytoplankton: diatoms, dinoflagellates, and cyanobacteria (also called blue-green algae). CDC launched the One Health Harmful Algal Bloom System (OHHABS) in 2016 to inform efforts to prevent human and animal illnesses associated with harmful algal bloom events. A total of 18 states reported 421 harmful algal bloom events, 389 cases of human illness, and 413 cases of animal illness that occurred during 2016-2018. The majority of harmful algal bloom events occurred during May-October $(413 ; 98 \%)$ and in freshwater bodies $(377 ; 90 \%)$. Human and animal illnesses primarily occurred during June-September $(378 ; 98 \%)$ and May-September (410; 100\%). Gastrointestinal or generalized illness signs or symptoms were the most frequently reported ( $>40 \%$ of human cases and $>50 \%$ of animal cases); however, multiple other signs and symptoms were reported. Surveillance data from harmful algal bloom events, exposures, and health effects provide a systematic description of these occurrences and can be used to inform control and prevention of harmful algal bloom-associated illnesses.

Harmful algal bloom events occur in salt, brackish, and fresh water. In bodies of water such as oceans and estuaries, diatoms or dinoflagellates form "tides" that produce toxins associated with seafood poisoning, including paralytic shellfish poisoning, or respiratory distress from inhalation of aerosolized toxins. Cyanobacteria predominantly bloom in fresh water such as lakes and rivers; they can produce microcystins, cylindrospermopsin, and other toxins that humans or animals might be exposed to through water contact, inhalation, or ingestion $(2,4)$. Animals that become ill or die can be sentinels for harmful algal bloom events. Behavioral and biological factors might increase the likelihood or magnitude of their exposures to toxins compared with human exposures (5).

CDC, in consultation with state and federal partners, designed and launched* OHHABS using a One Health ${ }^{\dagger}$ approach. Integrating technical expertise from a 2007-2011 harmful algal bloom surveillance project (2) and national waterborne and foodborne outbreak surveillance (https:// www.cdc.gov/nors/about.html), the reporting system links harmful algal bloom event data with human or animal illness data and uses standard definitions to classify harmful algal bloom events as suspected or confirmed and cases of human or animal illness as suspected, probable, or confirmed. $\$$ Animal illnesses or deaths are reported as single cases or in groups, such as flocks of birds. This summary describes data from OHHABS for January 1, 2016-December 31, 2018, in reports that were submitted by state health departments by March 18, 2020. SAS (version 9.4; SAS Institute) was used

\footnotetext{
*OHHABS partners and system development are described in more detail at https://www.cdc.gov/habs/ohhabs_tables_and_figures.html.

$\dagger$ One Health is defined by $\mathrm{CDC}$ as "a collaborative, multisectoral, and transdisciplinary approach - working at the local, regional, national, and global levels - with the goal of achieving optimal health outcomes recognizing the interconnection between persons, animals, plants, and their shared environment." https://www.cdc.gov/onehealth/index.html.

${ }^{\S}$ Harmful algal bloom events and cases reported to OHHABS are classified based on standard definitions. Suspected harmful algal bloom events are required to have observational/environmental data or associated illnesses as supporting evidence. Confirmed harmful algal bloom events are required to have either laboratory-based harmful algal bloom data or both observational/environmental data and at least one associated case of illness as supporting evidence. Harmful algal bloom-associated illness data are subject to a public health assessment process. Suspected human or animal cases must have experienced a harmful algal bloom exposure and signs/symptoms. Probable human or animal case classifications must be supported by one of the following: observational/ environmental data, laboratory-based harmful algal bloom data, or a professional medical diagnosis. Confirmed human or animal cases must be supported by one of the following: 1) clinical data confirming the exposure plus a professional medical diagnosis or other causes ruled out or 2) laboratory-based harmful algal bloom data plus a professional medical diagnosis and other causes ruled out. More detailed information is available at: https://www.cdc.gov/habs/pdf/ ohhabs-case-and-event-definitions-table-508.pdf.

OHHABS is available for voluntary reporting by public health agencies and their designated environmental health or animal health partners in the United States, District of Columbia, Federated States of Micronesia, Guam, Marshall Islands, Northern Mariana Islands, Palau, Puerto Rico, and U.S. Virgin Islands.
} 
to conduct descriptive analyses to characterize environmental conditions during harmful algal bloom events, harmful algal bloom-associated cases of human or animal illness, and results of environmental and clinical toxin testing.

A total of 18 states** $^{* *}$ voluntarily reported 421 harmful algal bloom events that occurred during 2016-2018, with the majority (88\%) classified as confirmed (Table 1). These events occurred predominantly during May-October (98\%), peaking in July (27\%). The majority (90\%) of the reported harmful algal bloom events occurred in freshwater bodies. Fewer than half of all reports (39\%) indicated that a visible scum had been observed. Laboratory testing for $372(88 \%)$ harmful algal bloom events was performed on water samples (98\%), algae or cyanobacteria $(7 \%)$, or food samples $(1 \%)$. Reasons for testing included environmental monitoring activities (79\%), citizen

\footnotetext{
** Alaska, Arizona, California, Connecticut, Florida, Kansas, Maryland, Michigan, Minnesota, Nevada, New York, North Carolina, Ohio, Oregon, Pennsylvania, Utah, Virginia, and Wisconsin.
}

TABLE 1. Characteristics of harmful algal bloom events $(n=421)-$ One Health Harmful Algal Bloom System (OHHABS), * United States, 2016-2018

\begin{tabular}{|c|c|}
\hline Characteristic & No. (\%) \\
\hline $\begin{array}{l}\text { Classification }^{\dagger} \\
\text { Confirmed } \\
\text { Suspected }\end{array}$ & $\begin{array}{r}370(88) \\
51(12)\end{array}$ \\
\hline $\begin{array}{l}\text { Water source type } \\
\text { Fresh } \\
\text { Brackish } \\
\text { Salt } \\
\text { Unknown }\end{array}$ & $\begin{array}{r}377(90) \\
14(3) \\
12(3) \\
18(4)\end{array}$ \\
\hline $\begin{array}{l}\text { Month } \$, q \\
\text { February } \\
\text { March } \\
\text { April } \\
\text { May } \\
\text { June } \\
\text { July } \\
\text { August } \\
\text { September } \\
\text { October } \\
\text { Unknown }\end{array}$ & $\begin{array}{r}1(-) \\
2(-) \\
3(1) \\
31(7) \\
65(15) \\
115(27) \\
99(24) \\
75(18) \\
28(7) \\
2(-)\end{array}$ \\
\hline $\begin{array}{l}\text { Scum observed } \\
\text { Laboratory testing performed }\end{array}$ & $\begin{array}{l}166(39) \\
372(88)\end{array}$ \\
\hline $\begin{array}{l}\text { Sample type tested** } \\
\text { Raw or ambient water } \\
\text { Algae or cyanobacteria } \\
\text { Food } \\
\text { Finished drinking water }\end{array}$ & $\begin{array}{r}363(98) \\
27(7) \\
4(1) \\
1(-)\end{array}$ \\
\hline $\begin{array}{l}\text { Reason for testing } \\
\text { Monitoring } \\
\text { Citizen complaint } \\
\text { Animal health event response } \\
\text { Human health event response } \\
\text { Fish illness or kill } \\
\text { Other } \\
\text { Odor } \\
\text { Unknown }\end{array}$ & $\begin{array}{r}295(79) \\
64(17) \\
17(5) \\
17(5) \\
4(1) \\
3(1) \\
1(-) \\
7(2)\end{array}$ \\
\hline
\end{tabular}

See table footnotes on the next column. complaints (17\%), or health events involving animals (5\%) or humans (5\%). Toxin results reported for 308 harmful algal bloom events (83\%) frequently identified microcystins (94\%); 35 (11\%) reports identified more than one type of toxin.

A total of 389 human cases of illness were reported, with 341 $(88 \%)$ classified as probable (Table 2). Approximately one half of cases $(199 ; 51 \%)$ resulted from a single, freshwater harmful algal bloom event that occurred in a large lake in July; extended to connected waterways, such as rivers, canals, and reservoirs; and spanned more than 3 months. At least 153 (39\%) of the 389 persons with cases were aged $<18$ years. Almost all (98\%) reported illnesses occurred during June-September. Signs and symptoms reported for $380(98 \%)$ cases indicated that affected persons most frequently experienced gastrointestinal (67\%); generalized (e.g., headache, fever, or lethargy) (43\%); dermatologic $(27 \%)$; or ear, nose, or throat-related $(16 \%)$ signs or symptoms. No deaths were reported. Time to onset of initial signs or symptoms was available for 124 persons who had a one-time exposure and ranged from 1 minute to 8 days.

TABLE 1. (Continued) Characteristics of harmful algal bloom events $(n=421)$ - One Health Harmful Algal Bloom System (OHHABS),* United States, 2016-2018

\begin{tabular}{lr}
\hline Characteristic & No. (\%) \\
\hline Testing results**,†† & \\
Toxins $\S$ & $308(83)$ \\
Microcystins & $291(94)$ \\
Anatoxin-A & $30(10)$ \\
Saxitoxin & $19(6)$ \\
Cylindrospermopsin & $4(1)$ \\
Nodularin & $3(1)$ \\
Ciguatoxin & $1(-)$ \\
Other & $1(-)$ \\
Cyanobacteria & $65(17)$ \\
Dinoflagellates & $8(2)$ \\
Gonyaulacales & $2(25)$ \\
Gymnodiniales & $3(38)$ \\
Peridiniales & $1(13)$ \\
Prorocentrales & $1(13)$ \\
Unknown & $2(25)$ \\
Raphidophyceans & $3(1)$ \\
Diatoms & $2(1)$ \\
Unknownףף & $23(7)$ \\
\hline
\end{tabular}

${ }^{*}$ A total of 18 states adopted OHHABS and voluntarily reported 421 harmful algal bloom events: Alaska, Arizona, California, Connecticut, Florida, Kansas, Maryland, Michigan, Minnesota, Nevada, New York, North Carolina, Ohio, Oregon, Pennsylvania, Utah, Virginia, and Wisconsin.

${ }^{\dagger}$ Event classification criteria are located at https://www.cdc.gov/habs/pdf/ ohhabs-case-and-event-definitions-table-508.pdf.

$\S$ Percentages do not sum to $100 \%$ as a result of rounding.

" Month was assigned based on data availability, using the following hierarchy: 1) bloom observation date, 2) month of bloom notification, and 3) earliest date of an associated human or animal case.

** Percentages might exceed $100 \%$ because multiple options could be selected.

t† Data collection was restricted to positive results from environmental testing.

$\S \S$ Multiple toxins were reported for 35 events, with microcystins as one of the toxin classifications detected in 33 events. Other toxins detected included anatoxin-a, cylindrospermopsin, nodularin, saxitoxin, or other unspecified toxins.

กศ Twenty-three reports did not include results from environmental testing. 
TABLE 3. Characteristics of animal exposure and illness $(n=413)$ associated with harmful algal bloom events $(n=42)-$ One Health Harmful Algal Bloom System (OHHABS), * 2016-2018

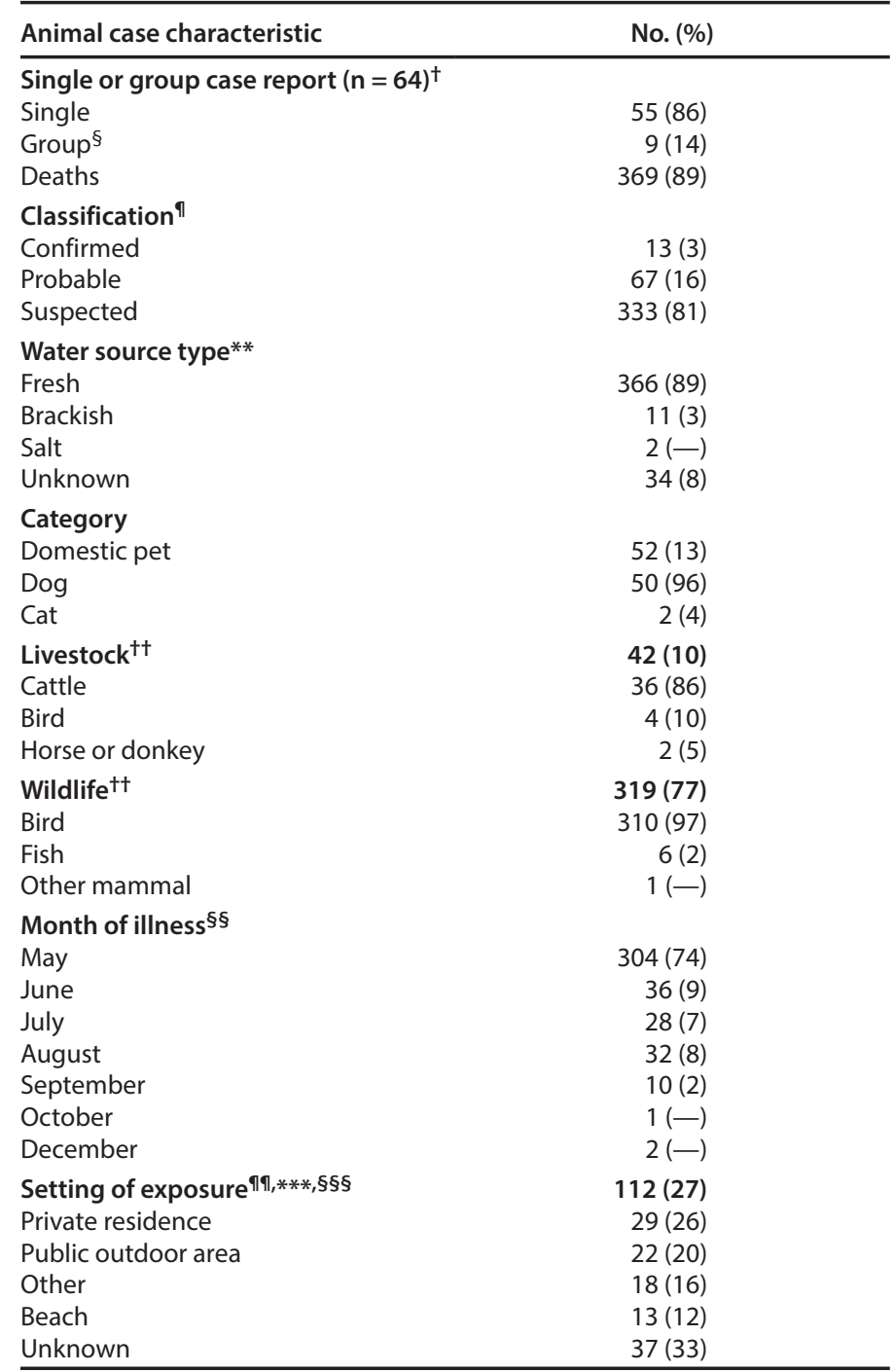

See table footnotes on the next column.

for 21 animals that had a one-time exposure and ranged from 15 minutes to 4 days. Veterinary medical care or treatment was provided to $25(6 \%)$ animals.

\section{Discussion}

Data reported to OHHABS by 18 states for 2016-2018 included 421 harmful algal bloom events, 389 cases of human illness, and 413 cases of animal illness. While the majority of harmful algal bloom events were classified as confirmed, the majority of human illnesses were classified as probable, and animal illnesses as suspected. These data reflect the launch of national public health surveillance for harmful algal bloom events and associated illnesses in the United States.

Epidemiologists, environmental health practitioners, public health laboratorians, and health communicators work together
TABLE 3. (Continued) Characteristics of animal exposure and illness $(n=413)$ associated with harmful algal bloom events $(n=42)$ - One Health Harmful Algal Bloom System (OHHABS), ${ }^{*}$ 2016-2018

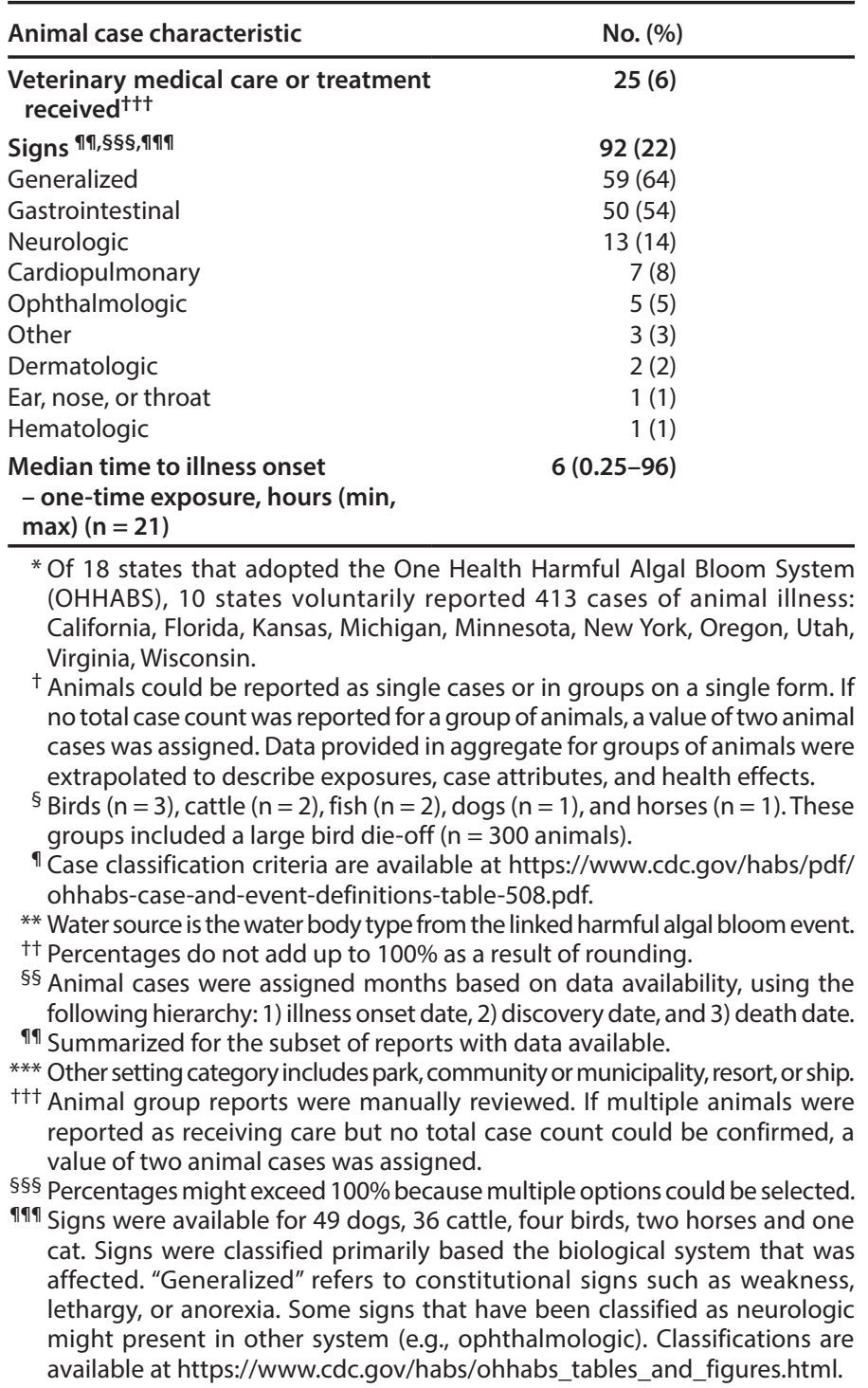

to increase awareness and understanding of public health risks of harmful algal bloom events. In addition, animal health professionals, environmental health professionals, and other stakeholders, such as academics, parks and recreation professionals, and citizen scientists, have knowledge and networks that strengthen the public health system's ability to detect, investigate, and report harmful algal bloom events and associated illnesses $(2,6)$. Poison control centers also can support case detection and investigation by sharing data with health departments. Illustrative of this approach, the Utah Poison Control Center shared data with the Utah Department of Health and entered data into OHHABS, including during a cyanobacterial bloom event in 2016 that resulted in one half of the total human cases reported for 2016-2018. 
Diagnostic testing for harmful algal bloom toxins is under development but is not currently available in routine clinical settings (7). Fewer than $5 \%$ of human or animal cases of illness were classified as confirmed on the basis of current OHHABS criteria, which require supporting evidence such as a medical diagnosis or clinical confirmation of a harmful algal bloom exposure. Health care providers can play a critical role by notifying health departments when they suspect harmful algal bloom-associated illnesses, considering harmful algal bloom-associated illness as a differential diagnosis, and assigning relevant International Classification of Diseases (ICD) codes (8). More access to confirmatory testing is needed to support public health surveillance.

Laboratory testing occurred in approximately $90 \%$ of harmful algal bloom events, most often related to environmental monitoring activities, citizen complaints, or health event responses. Many U.S. jurisdictions have developed programs to monitor harmful algal blooms and related tools that help communicate health risks from exposure to harmful algal bloom events. 99 Remote sensing (e.g., satellite imagery) and citizen scientist opportunities can supplement such efforts and might help to increase early detection of harmful algal bloom

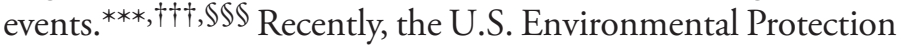
Agency released risk-based guidance for microcystins and cylindrospermopsin to assist with management of drinking water systems and recreational bodies of water $(9,10)$. This guidance, paired with water monitoring activities, notification systems, and community engagement, might be used to increase the completeness and accuracy of public health surveillance data reported in OHHABS, thereby increasing the data available for public health decision-making.

The findings in this report are subject to at least four limitations. First, these data are for the initial OHHABS data collection period; participation, data completeness, and data quality are anticipated to improve over time. Second, the number of reported events or illnesses underrepresents the total that occurred within or across states. Surveillance capacity and scope (e.g., inclusion of animal case reports) vary across jurisdictions and within this reporting period. Third, case and event definitions are not toxin-specific and do not yet have thresholds for test results from clinical specimen or environmental samples that correspond to acute health outcomes or public health action levels for toxins. Finally, harmful algal bloom events can exhibit geospatial, temporal, and toxin production variability, which makes environmental data more difficult to collect, interpret, and report.

\footnotetext{
$99 \mathrm{https} / /$ www.epa.gov/cyanohabs/state-habs-monitoring-programs-and-resources. *** https://oceanservice.noaa.gov/hazards/hab.

$\dagger \dagger$ https://www.epa.gov/water-research/cyanobacteria-assessment-network-cyan. $\$ \$ \$$ https://cyanos.org/\#programs.
}

\section{Summary}

What is already known on this topic?

Harmful algal blooms occur in fresh, brackish, and salt water throughout the United States. They can affect human and animal health and have ecological and economic impacts.

What is added by this report?

Eighteen states adopted use of the One Health Harmful Algal Bloom System and entered 421 reports during 2016-2018, including information about 389 human illnesses and at least 413 animal illnesses associated with harmful algal bloom events.

What are the implications for public health practice?

Information about harmful algal bloom exposures and health effects support efforts to detect these events and mitigate and prevent associated illnesses. Human, animal, and environmental health partners can work together to document the occurrence and impacts of harmful algal bloom events and characterize associated illnesses.

OHHABS is informed by local, state, and federal One Health partnerships. Data about harmful algal bloom exposures and health effects can be used to support prevention of harmful algal bloom-associated illnesses, which might increase because of warming waters or other climate change impacts (https://www.epa.gov/nutrientpollution/climate-change-andharmful-algal-blooms). OHHABS data can inform educational resources and outreach efforts by identifying factors that contribute to illnesses and informing targeted messages to populations at risk. More in-depth analyses to further characterize the data should support additional public health policy and prevention efforts. A continued One Health approach to surveillance, paired with scientific research (e.g., environmental science and human and animal health studies) findings and increased access to specimen testing, will add to the robustness and utility of the system.

\section{Acknowledgments}

State and local waterborne disease coordinators, epidemiologists, environmental health practitioners, laboratorians, toxicologists, and animal health practitioners; 2014-2016 One Health Harmful Algal Bloom System Working Group; Great Lakes Restoration Initiative, Chicago, Illinois; Kelly A. Barrett, Michael J. Beach, Katharine M. Benedict, Sarah A. Collier, Victoria M. Cuéllar, Kathleen E. Fullerton, Radhika Gharpure, Amy L. Jacobi, Kevin O'Laughlin, Division of Foodborne, Waterborne, and Environmental Diseases, National Center for Emerging and Zoonotic Infectious Diseases, CDC; Kayoko Shioda, Division of Viral Diseases, National Center for Immunization and Respiratory Diseases; Delaney Moore, BreAnne Osborn, Utah Department of Health; Sathya N. Chakravarthy, Karna LLC, Atlanta, Georgia, Irina Pyrkh, Brian G. Rachel, Northrop Grumman, Denver, Colorado. 
Corresponding author: Virginia A. Roberts, evl1@cdc.gov, 404-718-4871.

${ }^{1}$ Division of Foodborne, Waterborne, and Environmental Diseases, National Center for Emerging and Zoonotic Infectious Diseases, CDC; ${ }^{2}$ Division of Environmental Health Science and Practice, National Center for Environmental Health, CDC; ${ }^{3}$ Oak Ridge Institute for Science and Education, Oak Ridge, Tennessee; ${ }^{4}$ US Environmental Protection Agency, Research Triangle Park, North Carolina; ${ }^{5}$ Division of Environmental Laboratory Sciences, National Center for Environmental Health, CDC; ${ }^{6}$ Karna, LLC, Atlanta, Georgia.

\section{References}

1. Wells ML, Karlson B, Wulff A, et al. Future HAB science: directions and challenges in a changing climate. Harmful Algae 2020;91:101632. https:// doi.org/10.1016/j.hal.2019.101632

2. Backer LC, Manassaram-Baptiste D, LePrell R, Bolton B. Cyanobacteria and algae blooms: review of health and environmental data from the Harmful Algal Bloom-Related Illness Surveillance System (HABISS) 2007-2011. Toxins (Basel) 2015;7:1048-64. PMID:25826054 https:// doi.org/10.3390/toxins7041048

3. Adams CM, Larkin SL, Hoagland P, Sancewich B. Assessing the economic consequences of harmful algal blooms: A summary of existing literature, research methods, data, and information gaps. In: Shumway SE, Burkholder JM, Morton SL, eds. Harmful algal blooms: a compendium desk reference. 1st ed. Hoboken, NJ: John Wiley and Sons Ltd; 2018:33754. https://doi.org/10.1002/9781118994672.ch8

4. Backer LC, McNeel SV, Barber T, et al. Recreational exposure to microcystins during algal blooms in two California lakes. Toxicon 2010;55:909-21. PMID:19615396 https://doi.org/10.1016/j. toxicon.2009.07.006
5. Backer LC, Miller M. Sentinel animals in a One Health approach to harmful cyanobacterial and algal blooms. Vet Sci 2016;3:1-18. PMID:27152315 https://doi.org/10.3390/vetsci3020008

6. Nierenberg K, Hollenbeck J, Fleming LE, et al. Frontiers in outreach and education: the Florida red tide experience. Harmful Algae 2011;10:374-80. PMID:21532966 https://doi.org/10.1016/j. hal.2011.01.004

7. Wharton RE, Cunningham BR, Schaefer AM, Guldberg SM, Hamelin EI, Johnson RC. Measurement of microcystin and nodularin activity in human urine by immunocapture-protein phosphatase $2 \mathrm{~A}$ assay. Toxins 2019;11:729. PMID: 31847123 https://doi.org/10.3390/ toxins 11120729

8. Figgatt M, Muscatiello N, Wilson L, Dziewulski D. Harmful algal bloom-associated illness surveillance: lessons from reported hospital visits in New York, 2008-2014. Am J Public Health 2016;106:440-2. PMID:26794161 https://doi.org/10.2105/AJPH.2015.302988

9. US Environmental Protection Agency. Recommended human health recreational ambient water quality criteria or swimming advisories for microcystins and cylindrospermopsin. Washington, DC: US Environmental Protection Agency; 2019. https://www.epa.gov/wqc/ recommended-human-health-recreational-ambient-water-qualitycriteria-or-swimming-advisories

10. US Environmental Protection Agency. 2015 drinking water health advisories for two cyanobacterial toxins. Washington, DC: US Environmental Protection Agency; 2015. https://www.epa.gov/sites/ production/files/2017-06/documents/cyanotoxins-fact_sheet-2015.pdf 